\title{
Short-term effects of relaxation music on patients suffering from primary open-angle glaucoma
}

\author{
This article was published in the following Dove Press journal: \\ Clinical Ophthalmology \\ 22 October 2015 \\ Number of times this article has been viewed
}

\section{Thomas Bertelmann Ilse Strempel}

Department of Ophthalmology, Philipps-University Marburg, Baldingerstraße, Marburg, Germany
Correspondence: Thomas Bertelmann Department of Ophthalmology, Philipps-Universität Marburg, Baldingerstraße, 35033 Marburg, Germany Email thomas.bertelmann@staff.unimarburg.de
Purpose: To evaluate whether additive relaxation music (RM) has an adjuvant short-term effect on physiological and psychological parameters in patients with primary open-angle glaucoma.

Methods: Prospective, randomized clinical trial. Patients in the therapy group (TG) received a 30-minute RM via headphones, whereas members of the control group (CG) did not. Best corrected visual acuity, intraocular pressure, visual field testing, short- and long-term mental states, and blood levels of different stress hormones were analyzed and compared.

Results: A total of $25(61 \%) / 16(39 \%)$ patients were assigned to the TG/CG. Best corrected visual acuity, daily intraocular pressure, and short-term mental state (KAB) development were significantly better in the TG in comparison to controls. Visual field testing, long-term mental well-being (profile of mood states), and adrenalin, cortisol, and endothelin-I blood levels did not differ significantly between both groups.

Conclusion: Additive RM applied on a daily basis can positively impact various physiological and psychological parameters in the short term.

Keywords: primary open angle glaucoma, POAG, music therapy, intraocular pressure, IOP, mental health

\section{Introduction}

Glaucoma is the second-most leading cause of severe visual impairment and blindness in the world, ${ }^{1,2}$ and primary open-angle glaucoma (POAG) is by far the most frequent entity accounting for up to $85 \%$ of all glaucoma cases. ${ }^{3}$ As prevalence rises with age, the number of people affected will ascend from 60.5 million at the millennium to approximately 80 million in the year 2020..$^{2,4}$ Thus, the burden of direct ${ }^{5}$ and indirect medical costs ${ }^{6}$ will substantially increase in the future. ${ }^{7}$ Of equal importance are the reduction in the quality of life and the fear of becoming blind of each individual patient affected. ${ }^{8}$

Major improvements have been made within the last few decades with respect to medical options and surgical techniques to hamper further glaucomatous optic nerve head $(\mathrm{ONH})$ damage, all of them mainly focusing on reducing intraocular pressure (IOP) and increasing ocular hemodynamics as well as neuroprotection of retinal ganglion cells. ${ }^{9}$ Nevertheless, POAG remains an irreversible disease with no definite established cure until today. Innovative adjuvant and complementary treatment options are needed to support conventional care alternatives to achieve an overall better outcome.

Former reports indicate an unique personality type of the glaucoma patient ${ }^{10}$ comprising escalated hypochondriasis, hysteria, health concerns and psychosomatic complaints, depressions, reduced emotional stability and extreme nervousness, as 
well as elevated mental stress. ${ }^{10-15}$ It was demonstrated that mental stress can significantly elevate IOP levels ${ }^{16,17}$ and thus trigger glaucomatous $\mathrm{ONH}$ damage. Contrariwise, various self-relaxation methods, including relaxation music (RM), can counteract the aforementioned pathophysiological sequences, stabilize the current state of mind, ${ }^{18}$ reduce mental stress, and thus, lower IOP levels. ${ }^{19,20}$

The aim of this study was to evaluate whether additive RM has an adjuvant short-term effect on various physiological as well as psychological parameters on patients with POAG.

\section{Material and methods}

This investigation was performed in accordance with the Declaration of Helsinki of 1975 (1983 revision). The institutional review board of Philipps-Universität Marburg approved the protocol before study initiation (study 83-02). All patients were enrolled and randomized into the therapy group (TG) or control group (CG) after written consent was obtained from each subject following an explicit explanation of the purpose and potential side effects of each procedure. Inclusion criterion was the diagnosis of a POAG, irrespective of current treatment regimen and disease duration or previous glaucoma surgery. Exclusion criteria were all other glaucoma entities. All participants were instructed to continue their current glaucoma therapy to ensure that the RM was used as an adjuvant element in the TG. Randomization was paper based with a randomization list of 100 patients before starting the investigation.

On a prestudy visit within 10 days before the core study phase, the medical history of each patient was evaluated and best corrected visual acuity (BCVA) and $30^{\circ}$ blueyellow visual field (VF) testing were performed. ${ }^{21}$ Anamnesis included questions about various glaucoma, general medicine, and mental state issues (Table 1). BCVA was determined by performing subjective refraction and advising the patient afterward to read standard decimal visual acuity charts at $5 \mathrm{~m}$ distance. BCVA was then recorded in decimal notation. VF testing was perpetuated using the Humphrey HFA-IIC perimeter (Carl Zeiss Meditec AG, Jena, Germany). Five different pictures were handed to participants of the TG (including aqueous humor $[\mathrm{AH}]$ formation in the ciliary body, AH flow in the anterior part of the eye and drainage in the trabecular meshwork, as well as the front view of the $\mathrm{ONH}$ ). They were asked to memorize these pictures and to exercise the ability of visualization of the different intraocular structures and $\mathrm{AH}$ flow in the core study phase.

At days 1 and 10 of the core study phase, patients were asked to complete the profile of mood states (POMS)
Table I Baseline characteristics of patients randomized into the TG and CG

\begin{tabular}{|c|c|c|c|}
\hline & TG & CG & $P$-value \\
\hline $\begin{array}{l}\text { Number of } \\
\text { patients (\%) }\end{array}$ & $25(6 \mathrm{I})$ & $16(39)$ & $P=0.2 \mathrm{II}$ \\
\hline $\begin{array}{l}\text { Number of } \\
\text { eyes (\%) }\end{array}$ & $49(60)$ & $32(40)$ & $P=0.075$ \\
\hline Age (years) & $55.7 \pm 12.4$ & $56 \pm 12.7$ & $P=0.954$ \\
\hline $\begin{array}{l}\text { Sex } \\
\text { (male/female) (\%) }\end{array}$ & $7 / 18(28 / 72)$ & $7 / 9(44 / 56)$ & $P=0.060$ \\
\hline $\begin{array}{l}\text { Previous glaucoma } \\
\text { surgery (\%) }\end{array}$ & II (44) & $8(50)$ & $P=0.707$ \\
\hline $\begin{array}{l}\text { Glaucoma } \\
\text { eye drops (\%) }\end{array}$ & $19(76)$ & $8(50)$ & $P=0.087$ \\
\hline $\begin{array}{l}\text { General medical } \\
\text { problems (\%) }\end{array}$ & $23(92)$ & II (73) & $P=0.054$ \\
\hline $\begin{array}{l}\text { Vascular } \\
\text { dysregulation (\%) }\end{array}$ & $22(88)$ & $15(94)$ & $P=0.545$ \\
\hline Depression/stress (\%) & $15(60)$ & $10(62)$ & $P=0.873$ \\
\hline $\begin{array}{l}\text { Incriminatory social } \\
\text { environment (\%) }\end{array}$ & $8(32)$ & $4(25)$ & $P=0.631$ \\
\hline $\begin{array}{l}\text { Critical life } \\
\text { events (\%) }\end{array}$ & $15(60)$ & II (69) & $P=0.570$ \\
\hline $\begin{array}{l}\text { Reduced sleep } \\
\text { quality (\%) }\end{array}$ & $8(32)$ & $3(19)$ & $P=0.350$ \\
\hline
\end{tabular}

Abbreviations: TG, therapy group; CG, control group.

questionnaire immediately before the actual 30-minute treatment and control period. The POMS is a monopolar questionnaire consisting of 35 items to evaluate the prevailing mood of the last days to weeks (and thus long term). Four categories are retrieved, including melancholy, fatigue, motivation, and displeasure. Each of the 35 items is graded between 1 (absent) and 5 (fully present) and summed up. Thus, the higher the POMS score, the higher the psychological strain. ${ }^{22,23}$ POMS reporting was performed by the patients independently without the investigator's assistance and was done on a paper-based questionnaire.

At days 1 and 10 of the core study phase, immediately before and after the treatment and control period, a total of four blood samples were taken from each patient. Therefore, after careful disinfection of the cubital area, one of the cubital veins was punctured and a venous catheter (Vasofix (C) Braunüle(C), B Braun Melsungen AG, Melsungen, Germany) was placed and fixated. Patients had to lie in a supine position for at least 30 minutes prior to sampling of the first blood probe. Adrenalin, cortisol, and endothelin-I levels were analyzed at the Department of Laboratory Medicine, PhilippsUniversität Marburg, Germany and at the Department of Ophthalmology, Friedrich-Alexander-Universität Erlangen, Germany. Therefore, samples drawn for detection of adrenalin and cortisol levels were immediately frozen at $-80^{\circ} \mathrm{C}$ and probes for endothelin-I level determination were first 
centrifuged at 2,000 rpm/20 minutes with the Kendro Labs Biofuge Primo $^{\text {TM }}$ (Heraeus, Hanau, Germany). Serum overlap was then pipetted in $1.0 \mathrm{~mL}$ cryotubes ${ }^{\mathrm{TM}}$ (Sigma-Aldrich Co., St Louis, MO, USA) and stored at $-80^{\circ} \mathrm{C}$ in a freezer.

On each day of the core study phase, IOP was measured immediately before and after the treatment and control period. Patients were furthermore asked to complete the questionnaire for short-term mental well-being (KAB) at same time-points. IOP was evaluated using routine Goldman applanation tonometry. Therefore, the ocular surface was anesthetized and stained with Thilorbin(C) eye drops (OmniVision GmbH, Puchheim, Germany) and IOP was read from the measuring wheel. During each measurement, the measuring wheel was set to zero first and then moved upward by an assistant until pressure of the tonometer head equaled IOP to avoid any influence of the investigator. KAB in contrast to POMS is a one-dimensional and bipolar questionnaire to evaluate short-term effects of external stimuli on current mental well-being. Eight items are requested that can be graded between 1 (absent) and 6 (fully present). Thus, the higher the $\mathrm{KAB}$ score, the higher the current psychological strain. ${ }^{24} \mathrm{KAB}$ reporting in alignment with POMS measures was performed by the patients independently without the investigator's assistance and was done on a paper-based questionnaire.

On a post-study visit within 10 days after cessation of the core study phase, BCVA and VF measurements were repeated as described previously.

The treatment and control period consisted of a 30-minute time span on 10 consecutive days at the same time of day to cope with circadian rhythm. ${ }^{25}$ All patients were placed in a supine position on a convenient couch. In the TG, participants received $\mathrm{RM}^{26}$ (Vita musica II, Akustische Therapie für Augenpatienten by Ilse Strempel) via headphones (Sony MDR-CD570 ${ }^{\mathrm{TM}}$ ), whereas attendees allotted to the CG got no further additives but were instructed to relax. The RM used herein was a synergistic composition of relaxation-inducing music elements (harmonic music in heart rhythm of $60 \mathrm{bpm}$ ), subliminal binauricular beats, and instructions for breathing and relaxation as well as for visualization of different structures of the eye. ${ }^{27-29}$ Elements of the progressive muscle relaxation due to Jacobson ${ }^{30}$ and various nature sounds were also incorporated. Patients were instructed to choose the sound intensity they felt most comfortable with.

\section{Statistical analysis}

Tables and figures were designed applying Microsoft Office Word 2007C, Microsoft Office Excel 2007C, and SigmaPlot 12.0 C (Systat). Statistical analysis was performed using
SPSS 20 for Windows $@$ (IBM Corporation, Armonk, NY, USA). For testing statistical significance between both groups, the binomial distribution test, chi-square test, and Mann-Whitney $U$-test were conducted. IOP reduction was declared the primary end point, whereas all other measurements were secondary explorative end points. Significant differences between both groups were assumed if $P$-values were less than $0.05(P<0.05)$.

\section{Results}

A total of 41 patients (81 eyes) were included into this investigation with an overall age of $55.8 \pm 12.5$ years (mean value \pm standard deviation). Sex distribution indicated 14 male (34\%) and 27 female participants (66\%). In all, 25 patients (61\%) were randomized into the TG and 16 attendees (39\%) into the CG. The baseline characteristics of patients in each group are depicted in Table 1.

During the core study phase, IOP and KAB were evaluated on each day for both groups. $\triangle \mathrm{IOP}$ and $\triangle \mathrm{KAB}$ were calculated by subtraction of each parameter after the core study phase from before the core study phase. The corresponding results are displayed in Table 2 and Figures 1 and 2.

Table 2 Results of IOP ( $\mathrm{mmHg}$ ) and KAB (score) measurements for each day during the core study phase

\begin{tabular}{|c|c|c|c|}
\hline & TG $(n=49)$ & CG $(n=32)$ & $P$-value \\
\hline \multicolumn{4}{|c|}{$\Delta \mathrm{IOP}(\mathrm{mmHg})$} \\
\hline Day I & $-0.64 \pm 2.8$ & $1.5 \pm 2.85$ & $P=0.018$ \\
\hline Day 2 & $-1.0 \pm 2.66$ & $1.33 \pm 2.91$ & $P=0.010$ \\
\hline Day 3 & $-1.02 \pm 2.49$ & $0.93 \pm 1.22$ & $P=0.024$ \\
\hline Day 4 & $-1.75 \pm 2.2$ & $0.87 \pm 1.86$ & $P=0.001$ \\
\hline Day 5 & $-1.16 \pm 2.86$ & $0.77 \pm 2.1$ & $P=0.007$ \\
\hline Day 6 & $-0.82 \pm 2.45$ & $1.57 \pm 1.7$ & $P=0.002$ \\
\hline Day 7 & $-0.98 \pm 2.22$ & $0.57 \pm 2.48$ & $P=0.072$ \\
\hline Day 8 & $-0.43 \pm 2.59$ & $1.53 \pm 2.39$ & $P=0.024$ \\
\hline Day 9 & $-0.86 \pm 2.29$ & $1.73 \pm 1.62$ & $P=0.00 \mathrm{I}$ \\
\hline Day 10 & $-1.09 \pm 2.88$ & $1.3 \pm 1.57$ & $P=0.007$ \\
\hline \multicolumn{4}{|c|}{$\triangle K A B$ (score) } \\
\hline Day I & $-0.38 \pm 1.06$ & $0.55 \pm 1.07$ & $P=0.039$ \\
\hline Day 2 & $-0.7 I \pm 0.67$ & $0.02 \pm 0.77$ & $P=0.010$ \\
\hline Day 3 & $-0.57 \pm 0.83$ & $-0.16 \pm 0.68$ & $P=0.157$ \\
\hline Day 4 & $-0.47 \pm 0.84$ & $-0.13 \pm 0.32$ & $P=0.039$ \\
\hline Day 5 & $-0.64 \pm 0.53$ & $-0.05 \pm 0.56$ & $P=0.005$ \\
\hline Day 6 & $-0.49 \pm 0.73$ & $-0.30 \pm 0.44$ & $P=0.538$ \\
\hline Day 7 & $-0.39 \pm 0.52$ & $-0.1 \mathrm{I} \pm 0.4$ & $P=0.168$ \\
\hline Day 8 & $-0.37 \pm 0.63$ & $0.09 \pm 0.63$ & $P=0.088$ \\
\hline Day 9 & $-0.6 \pm 0.84$ & $-0.06 \pm 0.64$ & $P=0.015$ \\
\hline Day 10 & $-0.33 \pm 0.61$ & $0.23 \pm 0.95$ & $P=0.056$ \\
\hline
\end{tabular}

Notes: $\triangle \mathrm{IOP}(\mathrm{mmHg})$ and $\triangle \mathrm{KAB}$ were calculated by subtracting corresponding results after from the evaluation of both parameters before the 30-minute therapy/ control interval (negative KAB scores indicate improvement in overall mental wellbeing, whereas positive scores show an increase in mental strain).

Abbreviations: IOP, intraocular pressure; TG, therapy group; CG, control group. 


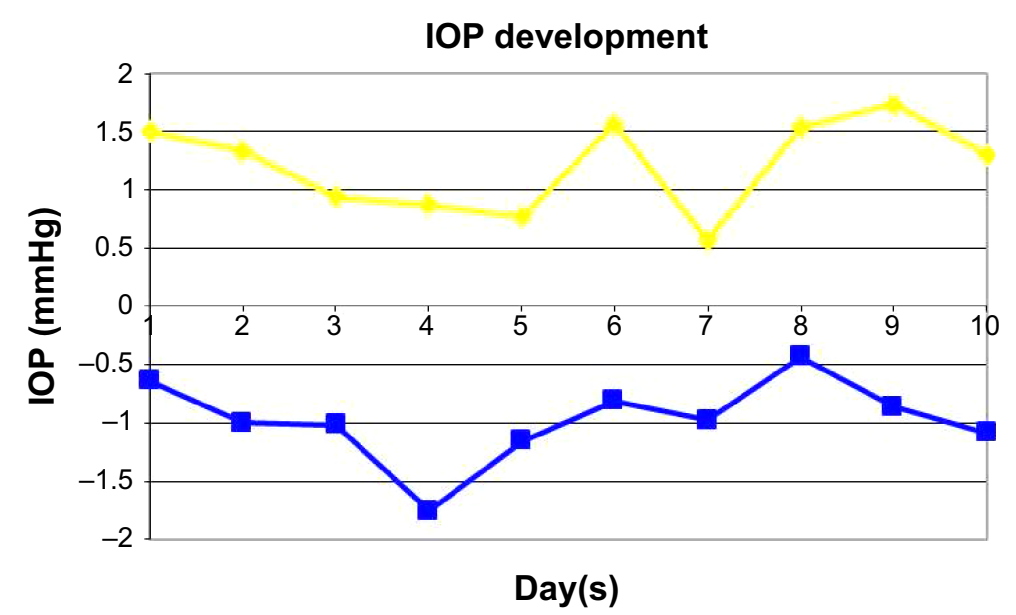

Figure I Mean change from baseline in IOP $(\mathrm{mmHg})$ during the I0-day core study phase (differences in IOP between before and after daily treatment).

Notes: Blue line = TG; yellow line = CG. Copyright (c) 2009. Reproduced with friendly permission from Bertelmann T. Musiktherapie für Glaukompatienten. Adjuvante Glaukomtherapie. Saarbrücken: Südwestdeutscher Verlag für Hochschulschriften; 2009. German. ${ }^{62}$

Abbreviations: IOP, intraocular pressure; TG, therapy group; CG, control group.

The effects of RM on BCVA, IOP, VF, KAB, POMS and various blood parameters between both groups at baseline and after the core study phase are summarized in Table 3.

\section{Discussion}

The beneficial effect of RM to reduce psychological stress and to improve overall mental well-being has emerged into the focus of interest in clinical research as well as routine clinical practice. Previous reports indicate that music interventions have a positive impact on psychological distress and anxiety, ${ }^{31-37}$ for instance, in patients suffering from coronary heart disease ${ }^{32}$ or undergoing hemodialysis treatment. ${ }^{31} \mathrm{RM}$ also reduces heart and respiratory rates as well as systolic blood pressure. ${ }^{32,34}$ Furthermore, a pain-reducing effect has been described in numerous research projects. ${ }^{32,34}$ Especially with respect to depression and mental stress reduction, $\mathrm{RM}$ showed excellent effects in the past. ${ }^{38,39}$ Mental stress significantly increases IOP, ${ }^{16,17,40}$ whereas different relaxation techniques significantly decrease the latter. ${ }^{19,20}$ Thus, the aim of this investigation was to evaluate the effects of additive RM on various physiological and psychological parameters in patients suffering from POAG. To the best of our knowledge, the effect of RM with respect to these parameters has not been described in a prospective and randomized clinical trial so far.

A total number of 100 patients were expected to participate in this investigation, but during the randomization procedure, only 41 gave their consent to attend. In specific, some patients were only interested in attending the study if randomized into the therapy group and therefore refused to be included even before the randomization procedure.

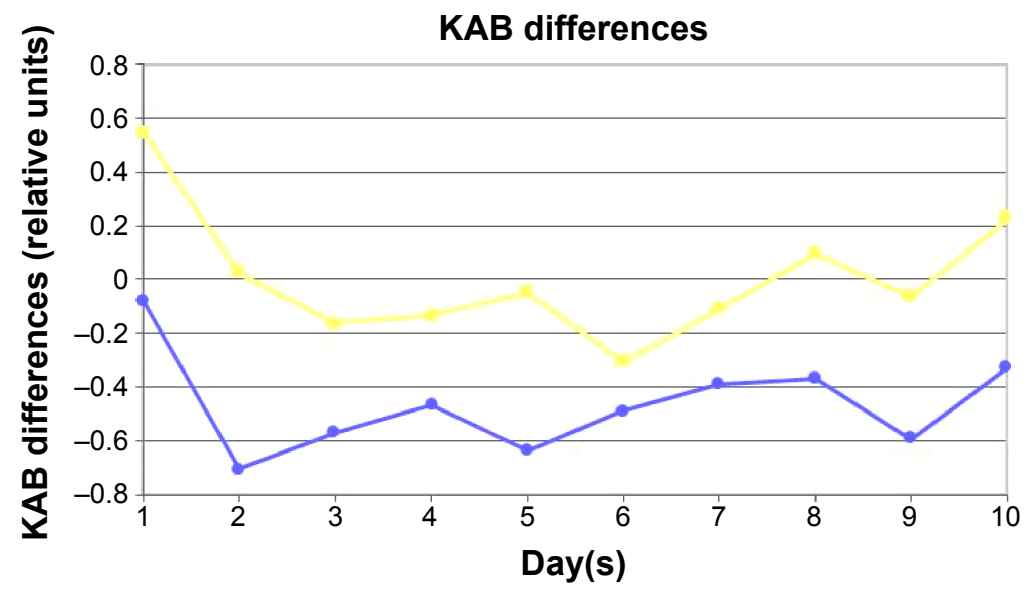

Figure 2 Mean change in $K A B$ scores during the 10-day core study phase (differences in KAB between before and after daily treatment).

Notes: Blue line = TG; yellow line = CG. Negative KAB scores indicate improvement in overall mental well-being, whereas positive scores show an increase in mental strain. Copyright @ 2009. Reproduced with friendly permission from Bertelmann T. Musiktherapie für Glaukompatienten. Adjuvante Glaukomtherapie. Saarbrücken: Südwestdeutscher Verlag für Hochschulschriften; 2009. German. ${ }^{62}$

Abbreviations: TG, therapy group; CG, control group. 
Table 3 Effects of RM on BCVA, IOP, VF, KAB, POMS, and various blood parameters between both groups after the core study phase

\begin{tabular}{|c|c|c|c|}
\hline & TG $(n=49)$ & CG $(n=32)$ & $P$-value \\
\hline \multicolumn{4}{|l|}{ BCVA (decimal) } \\
\hline Baseline & $0.88 \pm 0.23$ & $0.89 \pm 0.18$ & \multirow[t]{3}{*}{$P=0.002$} \\
\hline Final examination & $0.97 \pm 0.24$ & $0.86 \pm 0.2$ & \\
\hline$\triangle \mathrm{BCVA}(\%)$ & $0.09 \pm 0.12(9)$ & $-0.03 \pm 0.09(-3)$ & \\
\hline \multicolumn{4}{|l|}{ IOP $(\mathrm{mmHg})$} \\
\hline Baseline & $13.79 \pm 3.3$ & $13.9 \pm 2.97$ & \multirow[t]{3}{*}{$P=0.535$} \\
\hline Final examination & $13.64 \pm 3.76$ & $13.17 \pm 2.22$ & \\
\hline$\Delta \mathrm{IOP}(\mathrm{mmHg})$ & $-0.15 \pm 3.03$ & $-0.73 \pm 2.09$ & \\
\hline \multicolumn{4}{|c|}{$30^{\circ}$ visual field (mean deviation) } \\
\hline Baseline & $-5.3 \pm 5.9$ & $-3.2 \pm 6.8$ & \multirow[t]{3}{*}{$P=0.183$} \\
\hline Final examination & $-4.19 \pm 6.07$ & $-2.78 \pm 6.71$ & \\
\hline$\Delta$ mean deviation & $1.12 \pm 1.58$ & $0.37 \pm 1.21$ & \\
\hline \multicolumn{4}{|c|}{ Questionnaire for short-term mental well-being (KAB score) } \\
\hline Baseline & $2.67 \pm 0.51$ & $2.58 \pm 0.79$ & \multirow[t]{3}{*}{$P=0.573$} \\
\hline Final examination & $2.61 \pm 0.75$ & $2.72 \pm 0.78$ & \\
\hline$\triangle \mathrm{KAB}$ & -0.11 & $0.14 \pm 0.68$ & \\
\hline \multicolumn{4}{|c|}{ POMS score (melancholy) } \\
\hline Baseline & $20.52 \pm 8.12$ & $21.88 \pm 9.0$ & \multirow[t]{3}{*}{0.920} \\
\hline Final examination & $18.39 \pm 5.74$ & $19.56 \pm 7.64$ & \\
\hline$\Delta$ melancholy & $-2.13 \pm 3.82$ & $-4.44 \pm 4.0$ & \\
\hline \multicolumn{4}{|c|}{ POMS score (fatigue) } \\
\hline Baseline & $14.87 \pm 6.7$ & $|4.56 \pm 5.8|$ & \multirow[t]{3}{*}{0.989} \\
\hline Final examination & $12.87 \pm 5.77$ & $12.69 \pm 5.19$ & \\
\hline$\Delta$ fatigue & $-2.0 \pm 6.62$ & $-1.86 \pm 4.16$ & \\
\hline \multicolumn{4}{|c|}{ POMS score (motivation) } \\
\hline Baseline & $17.83 \pm 6.23$ & $19.06 \pm 5.80$ & \multirow[t]{3}{*}{$P=0.414$} \\
\hline Final examination & $19.87 \pm 6.15$ & $19.88 \pm 4.90$ & \\
\hline$\Delta$ motivation & $2.04 \pm 4.45$ & $0.8 \pm 3.71$ & \\
\hline \multicolumn{4}{|c|}{ POMS score (displeasure) } \\
\hline Baseline & $10.7 \pm 3.81$ & II. $.75 \pm 4.8$ & \multirow[t]{3}{*}{$P=0.673$} \\
\hline Final examination & $8.78 \pm 2.5$ & $10.06 \pm 4.77$ & \\
\hline$\Delta$ displeasure & $-1.9| \pm 2.7|$ & $-1.69 \pm 3.88$ & \\
\hline \multicolumn{4}{|c|}{ Adrenalin concentration $(\mathrm{pg} / \mathrm{mL})$} \\
\hline Time point I & $22.35 \pm 24.16$ & $19.19 \pm 22.42$ & \\
\hline Time point 2 & $21.91 \pm 20.43$ & $22.25 \pm 22.38$ & \\
\hline Time point 3 & $|3.57 \pm| 4.0 \mid$ & $25.13 \pm 28.61$ & \\
\hline Time point 4 & $15.04 \pm 27.42$ & $25.0 \pm 19.68$ & \\
\hline$\Delta$ Day I & $-0.43 \pm 17.98$ & $3.06 \pm 18.13$ & $P=0.440$ \\
\hline$\Delta$ Day 10 & $1.47 \pm 17.66$ & $-0.13 \pm 15.96$ & $P=0.448$ \\
\hline$\Delta$ Day I/day 10 & $-8.78 \pm 29.32$ & $5.94 \pm 35.15$ & $P=0.432$ \\
\hline \multicolumn{4}{|c|}{ Cortisol concentration $(\mu \mathrm{g} / \mathrm{dL})$} \\
\hline Time point I & $9.88 \pm 5.16$ & $8.29 \pm 3.43$ & \\
\hline Time point 2 & $9.04 \pm 5.27$ & $6.8 \pm 3.37$ & \\
\hline Time point 3 & $8.85 \pm 2.96$ & $9.19 \pm 4.95$ & \\
\hline Time point 4 & $7.361 \pm 3.07$ & $8.08 \pm 4.31$ & \\
\hline$\Delta$ Day I & $-0.84 \pm 3.09$ & $-1.49 \pm 1.52$ & $P=0.5 \mathrm{II}$ \\
\hline$\Delta$ Day 10 & $-1.49 \pm 2.17$ & $-1.11 \pm 1.93$ & $P=0.567$ \\
\hline$\Delta$ Day I/day I0 & $-1.03 \pm 4.18$ & $0.89 \pm 4.33$ & $P=0.627$ \\
\hline \multicolumn{4}{|c|}{ Endothelin concentration (pg/mL) } \\
\hline Time point I & $1.01 \pm 0.31$ & $1.16 \pm 0.5$ & \\
\hline Time point 2 & $1.23 \pm 0.47$ & $1.30 \pm 0.5$ & \\
\hline Time point 3 & $1.16 \pm 0.49$ & $1.1 \mathrm{I} \pm 0.42$ & \\
\hline Time point 4 & $1.23 \pm 0.36$ & $1.25 \pm 0.37$ & \\
\hline
\end{tabular}

(Continued)
Table 3 (Continued)

\begin{tabular}{llll}
\hline & TG $(\mathbf{n}=\mathbf{4 9})$ & CG $(\mathbf{n}=\mathbf{3 2})$ & $P$-value \\
\hline$\Delta$ Day I & $0.22 \pm 0.44$ & $0.14 \pm 0.4 \mathrm{I}$ & $P=0.596$ \\
$\Delta$ Day I0 & $0.06 \pm 0.33$ & $0.14 \pm 0.42$ & $P=0.573$ \\
$\Delta$ Day I/day I0 & $0.16 \pm 0.42$ & $-0.05 \pm 0.63$ & $P=0.37$ I \\
\hline
\end{tabular}

Notes: Negative KAB and POMS scores indicate improvement in overall mental well-being, whereas positive scores show an increase in mental strain.

Abbreviations: RM, relaxation music; BCVA, best corrected visual acuity; IOP, intraocular pressure; VF, visual field; POMS, profile of mood states; TG, treatment group; CG, control group.

Some patients withdrew their informed consent after being assigned to the CG. This caused the unequal size and characteristics distribution in both groups as shown in Table 1. Nevertheless, no significant differences could be obtained with respect to all baseline characteristics between both groups. This challenging recruitment shows that many patients do not have a sufficient understanding of the disease glaucoma and are unaware of the need of an excellent compliance to hamper further glaucomatous ONH damage, a fact that was already demonstrated in former reports as well. ${ }^{11,41-43}$ Contrariwise, patients with family members or friends suffering from glaucoma showed a significant better understanding of the importance to comply with prescribed (and additional) glaucoma therapy ${ }^{41}$ The bottom line is that all medical staff needs to intensify their efforts to educate glaucoma patients on these most important issues. Most of the patients included herein showed an intensive prior glaucoma care (surgical and/or medical), a distinct general medical history, as well as an altered mental state. This observation is in accordance with prior glaucoma studies ${ }^{12,44-46}$ and demonstrates that participants herein were aware of the facts discussed above. This in turn makes this investigation interesting because the additional effect of RM on a kind of typical glaucoma patient was presumably investigated.

As patients were instructed to choose the sound intensity they felt most comfortable with, the latter might have differed between patients in the TG. This in turn could have impacted the effect of RM, but choosing the intensity of choice in the individual patient should support individual relaxation ability. Furthermore, in the CG, no breathing exercises were conducted. As the latter were integrated in the RM program, the effect of RM might be overestimated, as per se breathing can increase parasympathetic system activity. But, to the best of our knowledge, the effect of breathing exercises on IOP levels was not demonstrated so far.

With regard to BCVA development, the data herein demonstrate a gain in the $\mathrm{TG}$ and a reduction in the $\mathrm{CG}$ that accounts for significant differences in BCVA after 10 days. This observation is of interest and is supported by former 
investigations. ${ }^{47,48} \mathrm{~A}$ decreasing IOP can increase ocular perfusion and thus reactivate optic nerve cells resting in the maintenance metabolism, which in turn can increase BCVA. ${ }^{47,49}$ $\mathrm{RM}$ is indeed able to significantly increase ocular perfusion. ${ }^{48}$ Any BCVA improvement is of particular importance with regard to patients' psychological state of mood because it immediately impacts quality of life and increases therapeutic compliance as well. This positive psychodynamic effect can significantly enhance subjective disease management of each glaucoma patient. ${ }^{50}$

During the core study phase, there was a daily decrease in IOP in the TG, whereas IOP increased in the CG (Figure 1 and Table 2). For each day with the exception of day 7 , a significant decrease in IOP during the music therapeutic treatment was demonstrated. This in turn shows the strong IOP reducing effect of RM applied herein in the short term, and so far, the reduction of prevailing IOP is the main target of almost all major glaucoma therapies. ${ }^{51-53}$ Former investigations revealed matchable effects, ${ }^{47,48}$ and thus, the IOP-lowering capability of $\mathrm{RM}$ is now established in more than 100 patients. Contrariwise, the comparison of days 1 and 10 herein showed no significant IOP-lowering effect in the TG. This might be attributed to the marginal number of patients included or to the brevity of the core study phase of 10 days. Indeed, there are reports indicating the need for a treatment phase of at least 3 weeks to establish long-term effects of music therapy. ${ }^{38}$ Eschstruth showed in a long-term evaluation after 3 months that patients listening to the same RM on a daily basis as used herein had a significant IOP reduction accounting for a decrease in IOPlowering eye drops of $37 \% .{ }^{47}$ In this study, no CG was carried along, and thus, a prospective and randomized trial evaluating the long-term effects of RM is now indicated.

In accordance with the daily IOP changes, results of the KAB showed daily improvements in current mental well-being as well. Oftentimes, the differences between TG and CG were significant (Figure 2 and Table 2). Former reports support our findings. ${ }^{47,48}$ Improving the mood state is of importance because a unique personality type of the glaucoma patient has been described, including hypochondriasis, hysteria, health concerns and psychosomatic complaints, depressions, reduced emotional stability, and extreme nervousness as well as mental stress, ${ }^{10-15}$ and improving these psychological markers has an immediate impact on therapeutic compliance as well as on quality of life ${ }^{50}$ and can furthermore reduce IOP as well. In this respect, it was formerly demonstrated that various structures of the central nervous system, including hypothalamus, corpora amygdaloidea, and the autonomic nervous system (sympathetic and parasympathetic part), are involved in the alliance of elevated stress levels and other various mental stimuli and mood states and an increased IOP. ${ }^{16,18,54-61} \mathrm{RM}$ can consequently counteract these pathological sequences and thus lower IOP as demonstrated herein. In contrast to KAB results and the short-term impact of RM, the POMS questionnaire did not display a significant improvement in long-term mental strain, but a tendency of mental state improvement. This again might be attributed to the marginal number of patients included or to the brevity of the core study phase.

VF testing surprisingly did not show a significant improvement in the TG, which was expected in analogy with BCVA development results. The reasons therefore remain vague, and further evaluations are needed to explain these findings. Nevertheless, an improvement in VF testing is, as discussed ahead in the BCVA section, of notably importance for each glaucoma patient. ${ }^{50}$

In respect to all blood parameters analyzed herein, no significant differences between both groups were detectable although expected, because former investigations demonstrated the significant effect of (mental) stress on various stress hormone levels. These results might be at least in part attributed to the low number of patients included.

The limitations of this investigation are the marginal number of patients enrolled, randomization difficulties, and the short study phase of 10 days. A prospective randomized trial with more patients assigned and a longer core study phase is indicated, though not easy to perform due to challenging recruitment as described herein. Nevertheless, this is the first prospective and randomized clinical trial incorporating a CG to evaluate whether additive RM has an adjuvant effect on various physiological (eg, IOP, stress hormones) as well as psychological parameters (eg, questionnaires of mood states).

\section{Conclusion}

In summary, an additive short-term effect of RM can be demonstrated for BCVA, IOP, and KAB development. As $\mathrm{RM}$ is an economical treatment option, easy to use, and combinable with almost any standard of care without side effects, the additional use can improve overall outcome in patients suffering from POAG.

\section{Acknowledgments}

There was no sponsor or funding organization involved in this study.

\section{Disclosure}

Thomas Bertelmann is a medical advisor at Novartis Pharma GmbH, Nuremberg, Germany and scientific staff of 
Philipps-University Marburg, Department of Ophthalmology, Marburg, Germany. The authors report no other conflicts of interest in this work.

\section{References}

1. Klein R, Klein BE. The prevalence of age-related eye diseases and visual impairment in aging: current estimates. Invest Ophthalmol Vis Sci. 2013;54(14):ORSF5-ORSF13.

2. Quigley HA. Number of people with glaucoma worldwide. $\mathrm{Br} J \mathrm{Oph}$ thalmol. 1996;80(5):389-393.

3. Mills D. The glaucomas - a review. Can Fam Physician. 1972;18(11): 63-66.

4. Quigley HA, Broman AT. The number of people with glaucoma worldwide in 2010 and 2020. Br J Ophthalmol. 2006;90(3):262-267.

5. Quigley HA, Cassard SD, Gower EW, Ramulu PY, Jampel HD, Friedman DS. The cost of glaucoma care provided to Medicare beneficiaries from 2002 to 2009. Ophthalmology. 2013;120(11): 2249-2257.

6. Hirneiß C, Kampik A, Neubauer AS. Volkswirtschaftliche Kosten von Augenerkrankungen [Macroeconomic costs of eye diseases]. Ophthalmologe. 2014;111(5):420-427. German.

7. Dirani M, Crowston JG, Taylor PS, et al. Economic impact of primary open-angle glaucoma in Australia. Clin Experiment Ophthalmol. 2011; 39(7):623-632.

8. Medeiros FA, Gracitelli CP, Boer ER, Weinreb RN, Zangwill LM, Rosen PN. Longitudinal changes in quality of life and rates of progressive visual field loss in glaucoma patients. Ophthalmology. 2015; 122(2):293-301.

9. Wentz SM, Kim NJ, Wang J, Amireskandari A, Siesky B, Harris A. Novel therapies for open-angle glaucoma. F1000Prime Rep. 2014;6:102.

10. Lim MC, Shiba DR, Clark IJ, et al. Personality type of the glaucoma patient. J Glaucoma. 2007;16(8):649-654.

11. Pappa C, Hyphantis T, Pappa S, et al. Psychiatric manifestations and personality traits associated with compliance with glaucoma treatment. J Psychosom Res. 2006;61(5):609-617.

12. Erb C, Batra A, Brömer A, Bayer AU, Müller-Schaaf B, Thiel HJ. Psychiatrische Manifestationen in Patienten mit primär chronischem Offenwinkelglaukom [Psychiatric manifestations in patients with primary open-angle glaucoma]. Ophthalmologe. 1993;90(6):635-639. German.

13. Igarashi Y, Sato E, Ito A, et al. Comparison of Yatabe-Guilford personality test results in retinitis pigmentosa and glaucoma patients. Jpn J Ophthalmol. 2003;47(1):1-5.

14. Erb C, Batra A, Lietz A, Bayer AU, Flammer J, Thiel HJ. Psychological characteristics of patients with normal-tension glaucoma. Graefes Arch Clin Exp Ophthalmol. 1999;237(9):753-757.

15. Emmerich GM. Psychosomatische Symptome bei rein somatischen Krankheiten unter anderem am Beispiel eines chronischen Offenwinkelglaukoms [Psychosomatic symptoms in somatic diseases - open-angle glaucoma for example]. Klin Monbl Augenheilkd. 2010;227(8):638-645. German.

16. Erb C, Brody S, Rau H. Einfluß von mentalem und physischem Streß auf den intraokulären Druck - eine Pilotstudie [Effect of mental and physical stress on intraocular pressure - a pilot study]. Klin Monbl Augenheilkd. 1998;212(5):270-274. German.

17. Grignolo FM, Bongioanni C, Carenini BB. Änderungen des Augeninnendrucks durch psychologischen Stress [Variations of intraocular pressure induced by psychological stress (author's transl)]. Klin Monbl Augenheilkd. 1977;170(4):562-569. German.

18. Suda M, Morimoto K, Obata A, Koizumi H, Maki A. Emotional responses to music: towards scientific perspectives on music therapy. Neuroreport. 2008;19(1):75-78

19. Kaluza G, Strempel I. Effects of self-relaxation methods and visual imagery on IOP in patients with open-angle glaucoma. Ophthalmologica. 1995;209(3):122-128.
20. Kaluza G, Strempel I, Maurer H. Stress reactivity of intraocular pressure after relaxation training in open-angle glaucoma patients. J Behav Med. 1996;19(6):587-598.

21. Sample PA, Bosworth CF, Weinreb RN. The loss of visual function in glaucoma. Semin Ophthalmol. 2000;15(4):182-193.

22. McNair DM, Lorr M, Droppleman LF. Manual for the Profile of Mood States. San Diego, CA: Educational and Industrial Testing Services; 1971.

23. Biehl B, Landauer A. Das Profile of Mood States (POMS). Mannheim: 1975.

24. Müller B, Basler HD. Kurzfragebogen zur aktuellen Beanspruchung (KAB). 1993. Manual. Göttingen: Beltz Test GmbH. Available from: https://www.unifr.ch/ztd/HTS/inftest/WEB-Informationssystem/de/4d ek01/3533c08af50611d380fc005004431da2/hb.htm. Accessed August 27, 2015.

25. Lemmer B. Grundlagen der Chronobiologie und Chronopharmakologie ausgewählter Krnakhietsbilder. In: Erb C, editor. Search on Glaucoma-Chronobiologie und Chronopharmakologie beim Glaukom. Amsterdam: Exerpta Medica Elsevier BV; 2006:4-14.

26. Strempel I. Keine Angst vor grünem Star. Ein Buch für Patienten: Ursachen-Hintergründe-Begleittherapie mit CD. Essen: KVC Verlag; 2009. German.

27. Lane JD, Kasian SJ, Owens JE, Marsh GR. Binaural auditory beats affect vigilance performance and mood. Physiol Behav. 1998;63(2): 249-252.

28. Wahbeh H, Calabrese C, Zwickey H, Zajdel D. Binaural beat technology in humans: a pilot study to assess neuropsychologic, physiologic, and electroencephalographic effects. J Altern Complement Med. 2007;13(2): 199-206.

29. Wahbeh H, Calabrese C, Zwickey H. Binaural beat technology in humans: a pilot study to assess psychologic and physiologic effects. J Altern Complement Med. 2007;13(1):25-32.

30. Jacobson E. Neuromuscular controls in man: methods of self direction in health and in disease. Am J Psychol. 1955;68(4):549-561.

31. Pothoulaki M, Macdonald RA, Flowers P, et al. An investigation of the effects of music on anxiety and pain perception in patients undergoing haemodialysis treatment. J Health Psychol. 2008;13(7):912-920.

32. Bradt J, Dileo C, Potvin N. Music for stress and anxiety reduction in coronary heart disease patients. Cochrane Database Syst Rev. 2013;12: CD006577.

33. Cooke M, Chaboyer W, Hiratos MA. Music and its effect on anxiety in short waiting periods: a critical appraisal. J Clin Nurs. 2005;14(2): 145-155.

34. Ebneshahidi A, Mohseni M. The effect of patient-selected music on early postoperative pain, anxiety, and hemodynamic profile in cesarean section surgery. J Altern Complement Med. 2008;14(7):827-831.

35. Aldridge D, Schmid W, Kaeder M, Schmidt C, Ostermann T. Functionality or aesthetics? A pilot study of music therapy in the treatment of multiple sclerosis patients. Complement Ther Med. 2005;13(1):25-33.

36. Lee OK, Chung YF, Chan MF, Chan WM. Music and its effect on the physiological responses and anxiety levels of patients receiving mechanical ventilation: a pilot study. J Clin Nurs. 2005;14(5):609-620.

37. Evans D. The effectiveness of music as an intervention for hospital patients: a systematic review. $J A d v$ Nurs. 2002;37(1):8-18.

38. Chan MF, Wong ZY, Thayala NV. The effectiveness of music listening in reducing depressive symptoms in adults: a systematic review. Complement Ther Med. 2011;19(6):332-348.

39. Choi AN, Lee MS, Lim HJ. Effects of group music intervention on depression, anxiety, and relationships in psychiatric patients: a pilot study. J Altern Complement Med. 2008;14(5):567-570.

40. de Torres-lucena M. [Behavior of ocular tension in a series of normal subjects under strong psychic stimulus]. Archivos Soc Oftalmol Hisp Am. 1950;10(7):743-754. Spanish.

41. Dietlein TS, Jordan J, Dinslage S, Jacobi PC, Krieglstein GK. Profil einer universitären Glaukomsprechstunde [Patient characteristics in a tertiary glaucoma center. Circumstances of treatment and attitudes of patients]. Ophthalmologe. 2005;102(5):502-506. German. 
42. Hoevenaars JG, Schouten JS, van den Borne B, Beckers HJ, Webers CA. Will improvement of knowledge lead to improvement of compliance with glaucoma medication? Acta Ophthalmol. 2008;86(8):849-855.

43. Ashaye AO, Adeoye AO. Characteristics of patients who dropout from a glaucoma clinic. J Glaucoma. 2008;17(3):227-232.

44. Erb C, Thiel HJ, Flammer J. The psychology of the glaucoma patient. Curr Opin Ophthalmol. 1998;9(2):65-70.

45. Gordon MO, Kass MA. The Ocular Hypertension Treatment Study: design and baseline description of the participants. Arch Ophthalmol. 1999; 117(5):573-583.

46. Ederer F, Gaasterland DE, Sullivan EK, Investigators A. The Advanced Glaucoma Intervention Study (AGIS): 1. Study design and methods and baseline characteristics of study patients. Control Clin Trials. 1994;15(4):299-325.

47. Eschstruth P. Einfluss akustischer und imaginativer Entspannungsmethoden auf den intraokularen Druck. Musiktherapie beim primären Offenwinkelglaukom [Inaugural - dissertation]. Marburg: PhilippsUniversität Marburg; 2004. German.

48. Dippel O. Musikmedizinische Einflüsse auf die Durchblutungssituation bei Patienten mit Glaukom [Inaugural - dissertation]. Marburg: Philipps-Universität Marburg; 2007. German.

49. Flammer J, Pache M, Resink T. Vasospasm, its role in the pathogenesis of diseases with particular reference to the eye. Prog Retin Eye Res. 2001;20(3):319-349.

50. McKean-Cowdin R, Wang Y, Wu J, Azen SP, Varma R, Group LALES. Impact of visual field loss on health-related quality of life in glaucoma: the Los Angeles Latino Eye Study. Ophthalmology. 2008;115(6): 941.e1-948.e1.

51. The effectiveness of intraocular pressure reduction in the treatment of normal-tension glaucoma. Collaborative Normal-Tension Glaucoma Study Group. Am J Ophthalmol. 1998;126(4):498-505.

52. The Advanced Glaucoma Intervention Study (AGIS): 7. The relationship between control of intraocular pressure and visual field deterioration. The AGIS Investigators. Am J Ophthalmol. 2000;130(4):429-440.
53. Heij1 A, Leske MC, Bengtsson B, Hyman L, Hussein M, Group EMGT. Reduction of intraocular pressure and glaucoma progression: results from the Early Manifest Glaucoma Trial. Arch Ophthalmol. 2002; 120(10):1268-1279.

54. Thiel R, Hollwich F. [Oculodiencephalic reflexes and eye tension]. Buch Augenarzt. 1955;23:166-209. German.

55. Von Sallmann L. The role of the central nervous system in the regulation of the intraocular pressure. Documenta Ophthalmologica. 1959;13(1):93-117.

56. Gloster J, Greaves DP. Effect of diencephalic stimulation upon intraocular pressure. Br J Ophthalmol. 1957;41(9):513-532.

57. Danilov GE, Sterkhova VI, Gurfinkel' KV, Egorkina SB. Der Effekt einer chronischen Stimulation des Hypothalamus und der Corpora amygdaloidea auf den Augeninnendruck [The effect of puncture actions on the ocular hypertension caused by chronic stimulation of the hypothalamus and amygdaloid body]. Fiziol Zh Im I M Sechenova. 1992;78(12):88-94. Russian.

58. Isakova LS, Danilov GE, Egorkina SB, Butolin EG. [Hormonal homeostasis and intraocular pressure in chronic emotional stress caused by influences acting on the amygdala]. Fiziol Zh SSSR Im I M Sechenova. 1989;75(1):124-130.

59. Mandl F. Sympathicuseingriffe in der Augenheilkunde. Blockade und Chirurgie des Sympathikus. Vienna: Springer Vienna; 1953:60-65.

60. Levinsohn G. Über den Einfluss des Halssympathikus auf das Auge. Arch Ophthalmol. 1902;55(1):144-174.

61. Khalfa S, Schon D, Anton JL, Liégeois-Chauvel C. Brain regions involved in the recognition of happiness and sadness in music. Neuroreport. 2005;16(18):1981-1984.

62. Bertelmann T. Musiktherapie für Glaukompatienten. Adjuvante Glaukomtherapie. Saarbrücken: Südwestdeutscher Verlag für Hochschulschriften; 2009. German.
Clinical Ophthalmology

\section{Publish your work in this journal}

Clinical Ophthalmology is an international, peer-reviewed journal covering all subspecialties within ophthalmology. Key topics include: Optometry; Visual science; Pharmacology and drug therapy in eye diseases; Basic Sciences; Primary and Secondary eye care; Patient Safety and Quality of Care Improvements. This journal is indexed on Submit your manuscript here: http://www.dovepress.com/clinical-ophthalmology-journal

\section{Dovepress}

PubMed Central and CAS, and is the official journal of The Society of Clinical Ophthalmology (SCO). The manuscript management system is completely online and includes a very quick and fair peer-review system, which is all easy to use. Visit http://www.dovepress.com/ testimonials.php to read real quotes from published authors. 